\title{
Observation of the Unusual Aggregation Kinetics of Colloidal Minerals in Acidic Solutions
}

\author{
RUI TIAN ${ }^{\mathrm{a}, \mathrm{b}}$, GANG YANG ${ }^{\mathrm{a}, *}$, XINMIN LIU $^{\mathrm{a}}$, CHENGZHI HUANG $^{\mathrm{b}, *}$, XIAODAN GAO $^{\mathrm{a}}$ and \\ HANG LI ${ }^{\mathrm{a}, *}$ \\ ${ }^{a}$ Chongqing Key Laboratory of Soil Multi-scale Interfacial Process, College of Resources and Environments, \\ Southwest University, Chongqing 400715, China \\ ${ }^{\mathrm{b}}$ College of Chemistry and Chemical Engineering, Southwest University, Chongqing 400715, China \\ e-mail: theobiochem@gmail.com; chengzhi@swu.edu.cn; lihangswu@163.com
}

MS received 17 January 2015; accepted 19 February 2015

\begin{abstract}
Hofmeister (Specific ion) effects have been considered as important to chemical science as Mendel's work was to genetics. In this work, the aggregation kinetics of montmorillonite colloids in $\mathrm{H}^{+}, \mathrm{Ag}^{+}$, $\mathrm{NH}_{4}^{+}, \mathrm{K}^{+}$and $\mathrm{Na}^{+}$solutions were measured in situ, detecting the unusual kinetics and ion specificity for $\mathrm{H}^{+}$. Activation energies that can quantitatively estimate the underlying specific ion effects change in the order of $\mathrm{H}^{+}<\mathrm{Ag}^{+}<\mathrm{NH}_{4}^{+}<\mathrm{K}^{+}<\mathrm{Na}^{+}$. Meanwhile, it was found that although the aggregation of montmorillonite colloids with lower particle densities results in higher activation energies, Hofmeister series will not be affected. It was sufficiently testified that interaction energies of colloidal particles with adsorbed ions show fine correlation with activation energies for colloidal aggregation, and larger interaction energy corresponds to lower activation energy. An attempt was made to quantitatively estimate the ion specificity for $\mathrm{H}^{+}$, and it was substantialized that the unusual ion specificity of $\mathrm{H}^{+}$is caused by steric effect.
\end{abstract}

Keywords. Aggregation kinetics; activation energy; colloidal particles; interaction energy; steric effect.

\section{Introduction}

The aggregation kinetics of proteins, colloids and minerals ranks as one of the cornerstone issues in a wide range of subjects. ${ }^{1-7}$ For colloidal particles, an increase of ionic strength generally results in the destabilization, which was finely interpreted by the Derjaguin-LandauVerwey-Overbeek (DLVO) theory. ${ }^{8,9}$ Nonetheless, the DLVO theory has recently encountered not a few failures, probably due to the neglect of ion specificities. ${ }^{10-12}$

Specific ion effects occur everywhere such as surface tension, ${ }^{13}$ zeta potential, ${ }^{14}$ protein precipitation, ${ }^{15,16}$ enzyme activity, ${ }^{17,18}$ osmotic behaviour, ${ }^{19}$ polymer aggregation $^{20-22}$ and colloidal stability. ${ }^{23-25}$ With use of differential scanning calorimetry, Thromann ${ }^{22}$ demonstrated that five potassium salts alter the stability of temperature responsive polymers in accordance to Hofmeister series. The dynamic light scattering (DLS) technique proves to be a powerful tool for the investigation of aggregation kinetics. In terms of the DLS results of Holthoff et al., ${ }^{26}$ the coagulation rate constants can be obtained for mono-disperse spherical colloidal particles. Recently, the critical coagulation concentrations $(C C C)$ and activation energies have been successively

*For correspondence determined for the aggregation of poly-disperse colloidal particles in alkali ion solutions, which thus provide a quantitative characterization of implicated specific ion effects. ${ }^{27,28}$ On the other hand, a number of electrical double layer (EDL) theories were developed to understand the interactions between colloidal particles and adsorbed ions..$^{29-33}$ Are the interaction energies related with the stability of colloidal particles or the activation kinetics (energies) for the aggregation processes? Furthermore, can the experimental activation energies for the aggregation of colloidal particles be theoretically interpreted by interaction energies? These issues are of central preoccupation while remain elusive currently.

Montmorillonite has been widely used in the manufacture of chemical and pharmaceutical intermediates, ${ }^{34}$ oil drilling industry as a drilling mud, ${ }^{35}$ soils as a component or additive ${ }^{36,37}$ and catalytic processes. ${ }^{38,39}$ In this work, the in-situ DLS measurements were performed to monitor the aggregation kinetics of montmorillonite colloids in $\mathrm{H}^{+}$as well as $\mathrm{Na}^{+}, \mathrm{K}^{+}, \mathrm{Ag}^{+}$ and $\mathrm{NH}_{4}^{+}$solutions with a wide range of ionic concentrations. Then the interaction energies between colloidal particles and adsorbed ions were correlated with the activation energies for colloidal aggregation, which were sufficiently testified by a number of cation 
Hofmeister series. On such basis, the mechanism for the unusual ion specificity for $\mathrm{H}^{+}$was clarified.

\section{Experimental}

\subsection{Materials}

All chemicals (reagent grade purity) were firstly filtered with a $0.22 \mu \mathrm{m}$ microfiltration membrane, and ultrapure water was passed through an AXLB1020 apparatus. $\mathrm{K}^{+}$-montmorillonite clays that were used in this work are nano-scale materials made up of one Al-O octahedral layer between two $\mathrm{Si}-\mathrm{O}$ tetrahedral layers. ${ }^{40}$ The montmorillonite colloids were prepared as follows: $50.0 \mathrm{~g}$ montmorillonite and $10 \mathrm{~mL} 0.1 \mathrm{~mol} / \mathrm{L} \mathrm{KOH}$ solutions were successively added into the beaker and then diluted by ultrapure water until $500 \mathrm{~mL}$. After 15 min intensive sonication, montmorillonite colloids were further diluted to $5 \mathrm{~L}$ by ultrapure water, and then those with the hydrodynamic diameter $<300 \mathrm{~nm}$ were extracted and collected using the static sedimentation method, ${ }^{41}$ which were estimated to have a particle density $(\rho)$ of $1.2 \mathrm{~g} / \mathrm{L}$. Note that the flame photometer detected that the concentration of $\mathrm{K}^{+}$in bulk colloids is less than $0.01 \mathrm{mmol} / \mathrm{L}$ and hence can be neglected. Finally, the $\mathrm{pH}$ of montmorillonite colloids was adjusted to 8.0 by $10 \mathrm{mmol} / \mathrm{L} \mathrm{KOH}$.

\subsection{Aggregation Kinetics Measurements}

The aggregation kinetics of montmorillonite colloids were measured in situ at $298 \mathrm{~K}$ in a screw-capped glass vial. Ionic solutions $\left(\mathrm{HNO}_{3}, \mathrm{NaNO}_{3}, \mathrm{KNO}_{3}, \mathrm{AgNO}_{3}\right.$ and $\mathrm{NH}_{4} \mathrm{NO}_{3}$ ) were added to $0.5 \mathrm{~mL}$ montmorillonite colloids until $10 \mathrm{~mL}$ and then mixed thoroughly. The samples that are ready for DLS measurements have ionic concentrations of $5,6,7,8,9,10,12,15,20,25$ and $30 \mathrm{mmol} / \mathrm{L}$ for $\mathrm{HNO}_{3}, 10,12,15,20,30,40,50$, 70, 100, 120 and $150 \mathrm{mmol} / \mathrm{L}$ for $\mathrm{KNO}_{3}, 40,50,60$, $80,100,120,150,200,300,400$ and $500 \mathrm{mmol} / \mathrm{L}$ for $\mathrm{NaNO}_{3}, 10,15,20,25,30,40,50,70,100$ and 120 $\mathrm{mmol} / \mathrm{L}$ for $\mathrm{NH}_{4} \mathrm{NO}_{3}$, and 10, 15, 20, 30, 40, 50, 70, 90, 100 and $120 \mathrm{mmol} / \mathrm{L}$ for $\mathrm{AgNO}_{3}$, respectively.

In accord with the previous works, ${ }^{27,42}$ a BI200SM multi-angle laser light scattering instrument (Brookhaven Instruments Corporation, New York, USA) with an autocorrelator of BI-9000AT was used for the in-situ measurement of the aggregation kinetics of montmorillonite colloids in different ionic solutions $\left(\mathrm{HNO}_{3}, \mathrm{NaNO}_{3}, \mathrm{KNO}_{3}, \mathrm{NH}_{4} \mathrm{NO}_{3}\right.$ and $\left.\mathrm{AgNO}_{3}\right)$. The power of the laser device equals $15 \mathrm{~mW}$ and is vertically polarized with a wavelength of $532 \mathrm{~nm}$. For each ionic concentration indicated above, data regarding the effective hydrodynamic diameters of montmorillonite aggregates were recorded every $30 \mathrm{sec}$ at a scattering angle of $90^{\circ}$.

The aggregation kinetics of montmorillonite colloids in ionic solutions can be described by the total average aggregation rate (TAA rate), ${ }^{27}$

$$
\tilde{v}_{T}\left(f_{0}\right)=\frac{1}{t_{0}} \int_{0}^{t_{0}} \frac{D(t)-D_{0}}{t} d t
$$

where, $f_{0}(\mathrm{mmol} / \mathrm{L})$ is the ionic concentration, $\tilde{v}_{T}\left(f_{0}\right)$ $(\mathrm{nm} / \mathrm{min})$ is the TAA rate from $t=0$ to a given time $t=t_{0}\left(t_{0}>0\right)$, and the upper limit of $t_{0}$ can be the ending time of the aggregation process. $D_{0}$ and $D(t)(\mathrm{nm})$ are respectively the effective hydrodynamic diameters of montmorillonite aggregates at the beginning and time $t_{0}$.

The TAA rate $\tilde{v}_{T}\left(f_{0}\right)$ can be correlated with the activation energy $\Delta E\left(f_{0}\right)$ with the expressions shown below, ${ }^{28}$

$$
\begin{aligned}
& \tilde{v}_{T}\left(f_{0}\right)=K \cdot f_{0} \cdot e^{-\frac{\Delta E\left(f_{0}\right)}{R T}} \quad\left(f_{0} \leq C C C\right) \\
& \tilde{v}_{T}\left(f_{0}\right)=K \cdot e^{-\frac{\Delta E\left(f_{0}\right)}{R T}} \quad\left(f_{0} \geq C C C\right)
\end{aligned}
$$

In Eq. $2, R(\mathrm{~J} / \mathrm{mol} \mathrm{K})$ is the gas constant and $T(\mathrm{~K})$ is the absolute temperature. $K$ can be regarded as a constant whether below or above the $C C C$, and its definitions were given as,

$$
\begin{array}{ll}
K=\tilde{v}_{T}(C C C) / C C C & \left(f_{0} \leq C C C\right) \\
K=\tilde{v}_{T}(C C C) & \left(f_{0} \geq C C C\right)
\end{array}
$$

\section{Results and Discussion}

The diameter growths of montmorillonite aggregates in $\mathrm{Na}^{+}$and $\mathrm{K}^{+}$solutions with a wide range of ionic concentrations are monitored in situ by DLS technique, see figure 1 . The aggregation rates for montmorillonite particles exhibit clear specific ion effects $\left(\mathrm{Na}^{+}<\mathrm{K}^{+}\right)$, in good agreement with the previous results. ${ }^{28}$ Notwithstanding, the particle density $(\rho)$ of montmorillonite colloids in this work approximates $0.06 \mathrm{~g} / \mathrm{L}$ and is less than that used previously $(\rho \approx 0.09 \mathrm{~g} / \mathrm{L})$. It indicates that the lower particle density results in significantly slower aggregation rates and further smaller hydrodynamic diameters. At $50 \mathrm{mmol} / \mathrm{L}(60 \mathrm{~min})$, the hydrodynamic diameters for $\rho \approx 0.06$ and $0.09 \mathrm{~g} / \mathrm{L}$ are 445.5 and $1375.2 \mathrm{~nm}$ in $\mathrm{Na}^{+}$solutions and 1658.6 and $2501.3 \mathrm{~nm}$ in $\mathrm{K}^{+}$solutions, respectively. The TAA rates $\tilde{v}_{T}\left(f_{0}\right)$ for the aggregation of montmorillonite particles $(\rho \approx 0.06 \mathrm{~g} / \mathrm{L})$ vs. ionic concentrations $f_{0}$ are calculated according to Eq. 1 and shown in figure 2a. For each cation species, the TAA rate curves present as two 


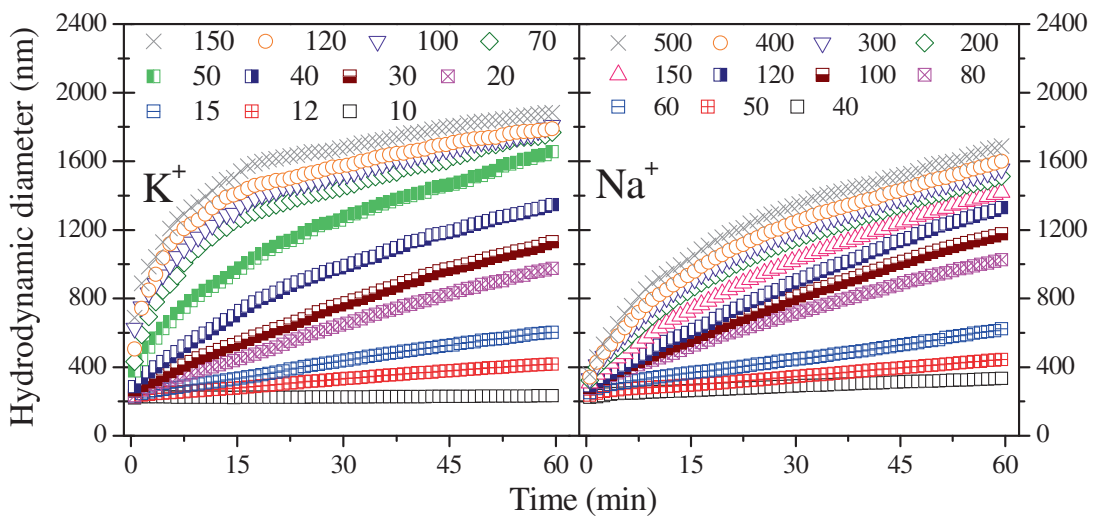

Figure 1. The time-evolution hydrodynamic diameters for the aggregation of montmorillonite colloids $(\rho \approx 0.06 \mathrm{~g} / \mathrm{L})$ in $\mathrm{K}^{+}$and $\mathrm{Na}^{+}$solutions of different ionic concentrations. Concentrations $(\mathrm{mmol} / \mathrm{L})$ are indicated in legends.

linear functions respectively at low and high concentration ranges, and the intersection point of these two lines stands for $C C C$. The $C C C$ values are equal to 78.9 and $139.7 \mathrm{mmol} / \mathrm{L}$ for $\mathrm{K}^{+}$and $\mathrm{Na}^{+}$, respectively, implying stronger ion specificity for $\mathrm{K}^{+}$. The $C C C$ values are close to those of $\rho \approx 0.09 \mathrm{~g} / \mathrm{L}$ (80.3 and $132.8 \mathrm{mmol} / \mathrm{L}$ for $\mathrm{K}^{+}$and $\mathrm{Na}^{+}$) and seem not very sensitive to the change of particle densities $(\rho)$, different from the scenarios of hydrodynamic diameters and TAA rates.

The aggregation kinetics for montmorillonite particles in ionic solutions are further characterized by activation energy $(\Delta E)$,

In $\mathrm{K}^{+}$solution:

$$
\begin{aligned}
\Delta E\left(f_{0}\right)= & -R T \ln \left(-9.054 / f_{0}+1.115\right) \\
& f_{0} \leq 78.9 \mathrm{mmol} / \mathrm{L}
\end{aligned}
$$

In $\mathrm{Na}^{+}$solution:

$$
\begin{aligned}
\Delta E\left(f_{0}\right)= & -R T \ln \left(-34.12 / f_{0}+1.244\right) \\
& f_{0} \leq 139.7 \mathrm{mmol} / \mathrm{L}
\end{aligned}
$$

The activation energies that represent functions of ionic concentrations increase linearly with the ionic concentrations below $C C C$ and remain the plateau above $C C C$ (i.e., $\Delta E \approx 0$ for $f_{0} \geq C C C$ ) (figure $2 b$ ). The activation energies for the aggregation of montmorillonite particles increase as $\mathrm{K}^{+}<\mathrm{Na}^{+}$, consistent with the hydrodynamic- diameter, TAA-rate and $C C C$ results. It explicitly shows that montmorillonite particles with lower particle density $(\rho)$ correspond to higher activation energies.

Then the time-evolution diameter growths of montmorillonite aggregates in $\mathrm{H}^{+}, \mathrm{NH}_{4}^{+}$and $\mathrm{Ag}^{+}$solutions with a wide range of ionic concentrations are measured

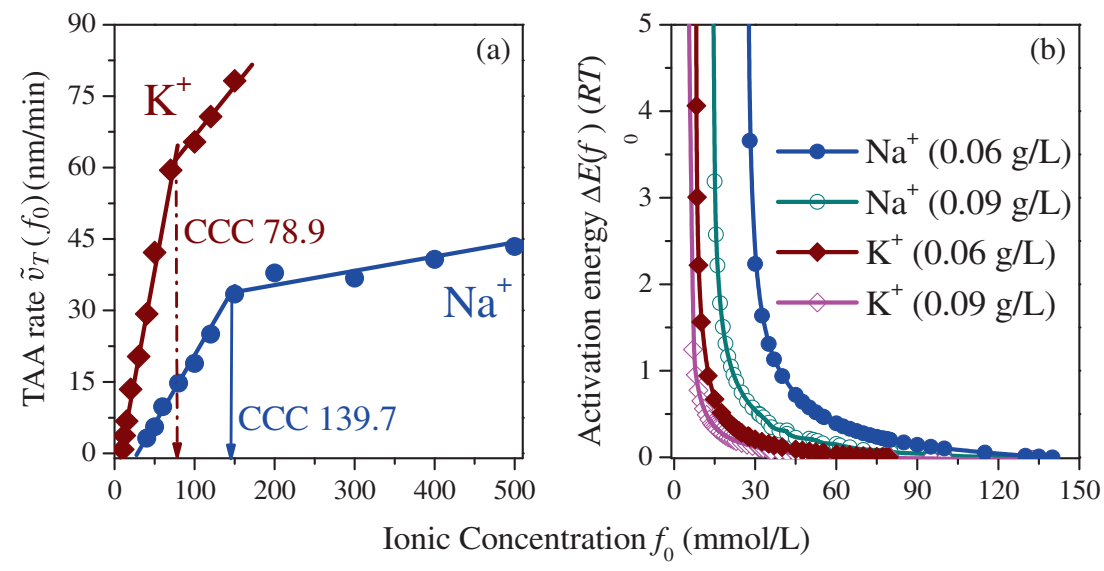

Figure 2. (a) The TAA rates $\tilde{v}_{T}\left(f_{0}\right)$ for the aggregation of montmorillonite particles $(\rho \approx 0.06 \mathrm{~g} / \mathrm{L})$ in $\mathrm{Na}^{+}$and $\mathrm{K}^{+}$solutions as a function of ionic concentration $f_{0}$ and; (b) The activation energies $\Delta E\left(f_{0}\right)$ vs. ionic concentrations $f_{0}$ for the aggregation of montmorillonite particles $(\rho \approx 0.06$ and $0.09 \mathrm{~g} / \mathrm{L})$ in $\mathrm{K}^{+}$and $\mathrm{Na}^{+}$solutions. 


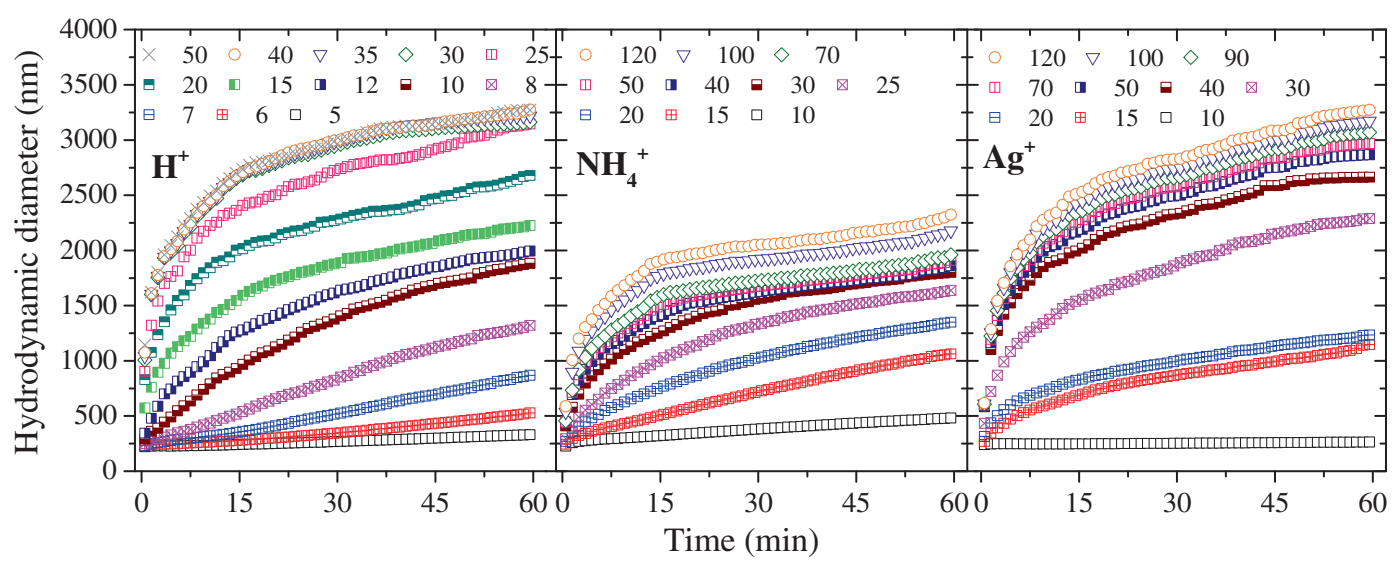

Figure 3. The time-evolution hydrodynamic diameters for the aggregation of montmorillonite particles $(\rho \approx 0.06 \mathrm{~g} / \mathrm{L})$ in $\mathrm{H}^{+}, \mathrm{NH}_{4}^{+}$, and $\mathrm{Ag}^{+}$solutions of different ionic concentrations. Concentrations $(\mathrm{mmol} / \mathrm{L})$ are indicated in legends.

in the same way as those in $\mathrm{Na}^{+}$and $\mathrm{K}^{+}$solutions (figure 3). An obviously faster diameter growth than in $\mathrm{Na}^{+}$and $\mathrm{K}^{+}$solutions has been detected in $\mathrm{H}^{+}$ solutions; e.g., at $40 \mathrm{mmol} / \mathrm{L}(60 \mathrm{~min})$, the diameters are equal to 333.9 (9.9), 1349.5 (4.0) and $3308.7 \mathrm{~nm}$ in $\mathrm{Na}^{+}, \mathrm{K}^{+}$and $\mathrm{H}^{+}$solutions, respectively. Note that the ratios of $\mathrm{H}^{+}$vs. other cations are given in parentheses. The diameter growths in $\mathrm{NH}_{4}^{+}$and $\mathrm{Ag}^{+}$solutions are also slower than that in $\mathrm{H}^{+}$solutions (figure $3)$. At $40 \mathrm{mmol} / \mathrm{L}(60 \mathrm{~min})$, the diameters of montmorillonite aggregates amount to 1867.2 (1.8), 1349.5 (2.0) and $3308.7 \mathrm{~nm}$ in $\mathrm{NH}_{4}^{+}, \mathrm{Ag}^{+}$and $\mathrm{H}^{+}$solutions, respectively.

As indicated in the plots of TAA rates (figures 2 and 4), the $C C C$ value of $\mathrm{H}^{+}, \mathrm{K}^{+}, \mathrm{Na}^{+}, \mathrm{NH}_{4}^{+}$and $\mathrm{Ag}^{+}$ are equal to $25.6,78.9,139.7,35.5$ and $41.9 \mathrm{mmol} / \mathrm{L}$, respectively. It states that $\mathrm{NH}_{4}^{+}$and $\mathrm{Ag}^{+}$have stronger ion specificities than $\mathrm{K}^{+}$and $\mathrm{Na}^{+}$while all these cations are significantly inferior to $\mathrm{H}^{+}$. Among the univalent cations, $\mathrm{H}^{+}$should be the one corresponding to the strongest ion specificity. At $10 \mathrm{mmol} / \mathrm{L}$, the aggregation does not occur in $\mathrm{Na}^{+}$solutions and has just started in $\mathrm{K}^{+}$solutions $(\mathrm{TAA}=0.8 \mathrm{~nm} / \mathrm{min}$ ); although the TAA rates in $\mathrm{NH}_{4}^{+}$and $\mathrm{Ag}^{+}$solutions $(7.3$ and $9.9 \mathrm{~nm} / \mathrm{min})$ are larger, they are substantially smaller as compared to that of $\mathrm{H}^{+}$solutions $(40.4 \mathrm{~nm} / \mathrm{min})$. It can be assumed that below $C C C$, the TAA rates increase in the order of $\mathrm{Na}^{+}<\mathrm{K}^{+}<\mathrm{NH}_{4}^{+}<\mathrm{Ag}^{+}<\mathrm{H}^{+}$. The change trend of TAA rates is applicable to any other ionic concentration; e.g., at $40 \mathrm{mmol} / \mathrm{L}$, the TAA rates for $\mathrm{Na}^{+}, \mathrm{K}^{+}$, $\mathrm{NH}_{4}^{+}$and $\mathrm{Ag}^{+}$and $\mathrm{H}^{+}$are calculated to be 3.2, 29.3, $76.0,107.1$ and $151.3 \mathrm{~nm} / \mathrm{min}$, respectively. The activation energies $(\Delta E)$ for the aggregation of montmorillonite particles in $\mathrm{H}^{+}, \mathrm{NH}_{4}^{+}$and $\mathrm{Ag}^{+}$solutions are calculated by Eq. 2 ,
In $\mathrm{H}^{+}$solution:

$$
\begin{aligned}
\Delta E\left(f_{0}\right)= & -R T \ln \left(-5.766 / f_{0}+1.226\right) \\
& f_{0} \leq 25.6 \mathrm{mmol} / \mathrm{L}
\end{aligned}
$$

In $\mathrm{NH}_{4}^{+}$solution:

$$
\begin{aligned}
\Delta E\left(f_{0}\right)= & -R T \ln \left(-10.18 / f_{0}+1.287\right) \\
& f_{0} \leq 35.5 \mathrm{mmol} / \mathrm{L}
\end{aligned}
$$

In $\mathrm{Ag}^{+}$solution:

$$
\begin{aligned}
\Delta E\left(f_{0}\right)= & -R T \ln \left(-8.496 / f_{0}+1.203\right) \\
& f_{0} \leq 41.9 \mathrm{mmol} / \mathrm{L}
\end{aligned}
$$

Figure $4 \mathrm{~d}$ shows that the activation energies $(\Delta E)$ below $C C C$ are significantly less in $\mathrm{H}^{+}$solutions than those in $\mathrm{K}^{+}, \mathrm{NH}_{4}^{+}$and $\mathrm{Ag}^{+}$solutions. The activation energies below $\mathrm{CCC}$ increase as $\mathrm{H}^{+}<\mathrm{Ag}^{+}<\mathrm{NH}_{4}^{+}<$ $\mathrm{K}^{+}<\mathrm{Na}^{+}$, explicitly showing the unusual aggregation kinetics and ion specificity for $\mathrm{H}^{+}$. The $\Delta E$ values in 10 (20) $\mathrm{mmol} / \mathrm{L} \mathrm{H}^{+}, \mathrm{Ag}^{+}, \mathrm{NH}_{4}^{+}, \mathrm{K}^{+}$solutions are equal to $0.43 R T$ (0.06RT), 1.32RT (0.25RT), 1.03RT (0.25RT) and $1.56 R T(0.41 R T)$, respectively. The $\Delta E$ value in $20 \mathrm{mmol} / \mathrm{L} \mathrm{Na}^{+}$solutions can be regarded as infinite because the aggregation has not started at all, while at the same concentration, the aggregation in $\mathrm{H}^{+}$solutions can be almost regarded as spontaneous. At any specified ionic concentration, the $\Delta E$ values of $\mathrm{K}^{+}$and $\mathrm{NH}_{4}^{+}$and $\mathrm{Ag}^{+}$are considerably larger those of $\mathrm{H}^{+}$. The sequence of $\Delta E\left(\mathrm{~K}^{+}\right)<\Delta E\left(\mathrm{Na}^{+}\right)$has been interpreted by polarization effect ${ }^{28}$, and the sequences of the other cations will be elaborated below.

Recently, a significant improvement to the classical EDL theory has been made in our group ${ }^{43}$ by considering the steric, polarization and valence effects, which provides an effective method to estimate the interaction 

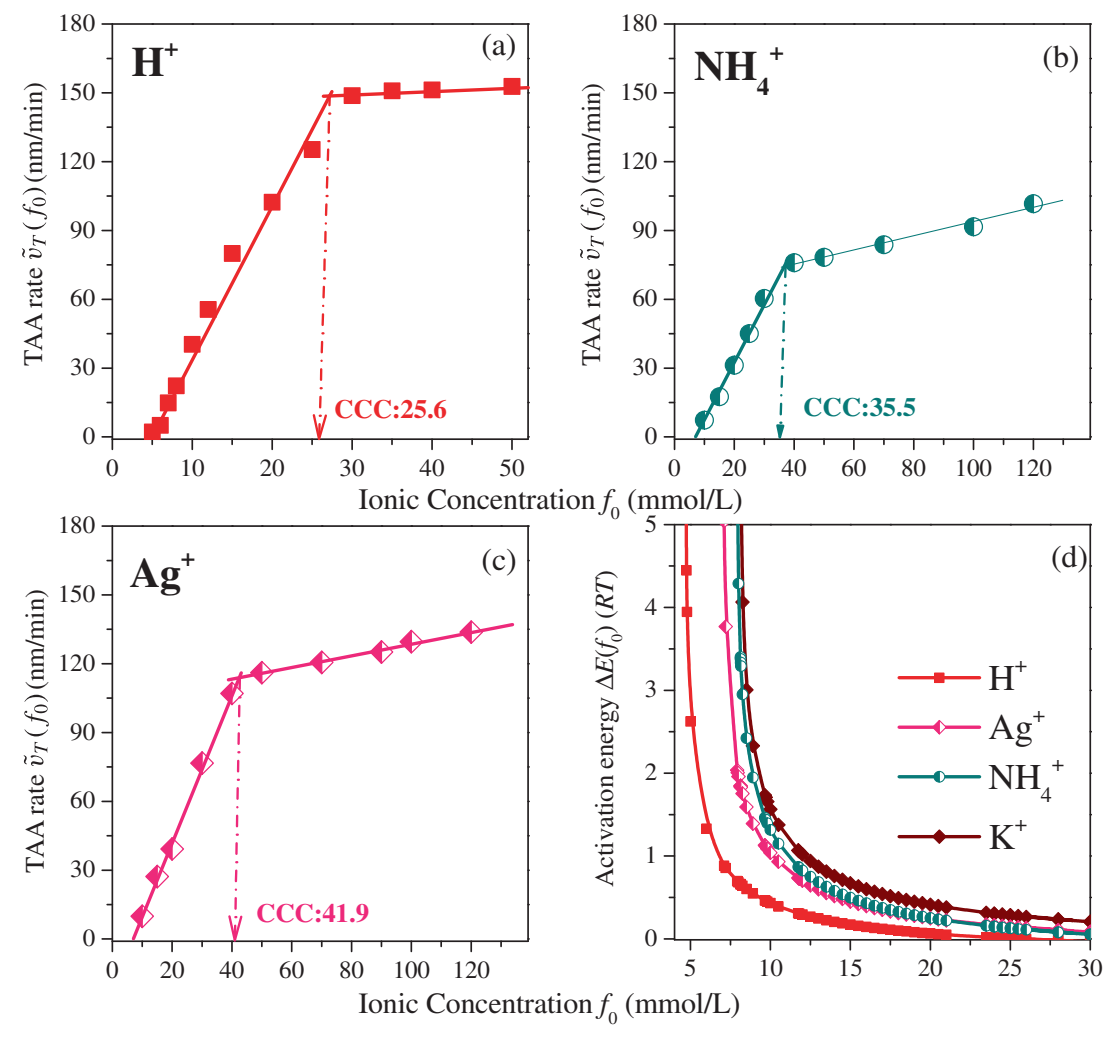

Figure 4. The TAA rates $\tilde{v}_{T}\left(f_{0}\right)$ for the aggregation of montmorillonite particles $(\rho \approx 0.06 \mathrm{~g} / \mathrm{L})$ in (a) $\mathrm{H}^{+}$, (b) $\mathrm{NH}_{4}^{+}$, and (c) $\mathrm{Ag}^{+}$solutions as a function of ionic concentration $f_{0}$ as well as (d) The activation energies $\Delta E\left(f_{0}\right)$ vs. ionic concentration $f_{0}$ for the aggregation of montmorillonite particles $(\rho \approx 0.06$ $\mathrm{g} / \mathrm{L})$ in $\mathrm{H}^{+}, \mathrm{NH}_{4}^{+}, \mathrm{Ag}^{+}$, and $\mathrm{K}^{+}$solutions.

energy $(w)$ between colloidal particles and adsorbed ions,

$$
\begin{aligned}
w & =w_{c}+w_{s}+w_{p} \\
& =Z F \varphi_{r}+p \kappa\left(\varphi_{r}-\varphi_{1 / \kappa}\right) \\
& =\left(\frac{\varphi_{r}}{\varphi_{0}}+\frac{p \kappa}{Z F} \frac{\varphi_{r}}{\varphi_{0}}-\frac{p \kappa}{Z F} \frac{\varphi_{1 / \kappa}}{\varphi_{0}}\right) Z F \varphi_{0} \\
& \approx\left(\frac{\varphi_{r}}{\varphi_{0}}+\frac{p \kappa}{Z F} \frac{\varphi_{r}}{\varphi_{0}}\right) Z F \varphi_{0} \\
& =\Pi_{i} Z F \varphi_{0}
\end{aligned}
$$

where $w_{c}, w_{s}$ and $w_{p}$ represent the interaction energies of the classic theory, steric hindrance and polarization effect, respectively. $Z$ is the ion valence, $F$ is the Faraday constant, $p$ is the dipole moment of the cation, and $\varphi_{0}$ is the surface potential, while $\varphi_{r}$ and $\varphi_{1 / \kappa}$ are respectively the potentials with distances of $r$ (radius of the cation) from the charged surface and at $1 / \kappa$ (the upper limit of EDL). Note that $\varphi_{1 / \kappa}$ approaches the null point because of situating at the ending of the EDL; that is, $\varphi_{1 / \kappa} \approx 0$.

Alkali cations in the EDL are significantly polarized by the strong electric fields $\left(10^{8} \sim 10^{9} \mathrm{~V} / \mathrm{m}\right)$ resulting from the surface charges of montmorillonite particles, and polarization effects increase as $\mathrm{Li}^{+}<$ $\mathrm{Na}^{+}<\mathrm{K}^{+}<\mathrm{Rb}^{+}<\mathrm{Cs}^{+}$. ${ }^{44}$ According to Eq. 9, larger polarization effect enhances the interaction energy. It has been stated before that activation energy is also closely associated with polarization effect. ${ }^{28}$ In the case of alkali cations $\left(\mathrm{Li}^{+} \sim \mathrm{Cs}^{+}\right)$, stronger polarization effect $(p)$ leads to larger interaction energy $(w)$, and this

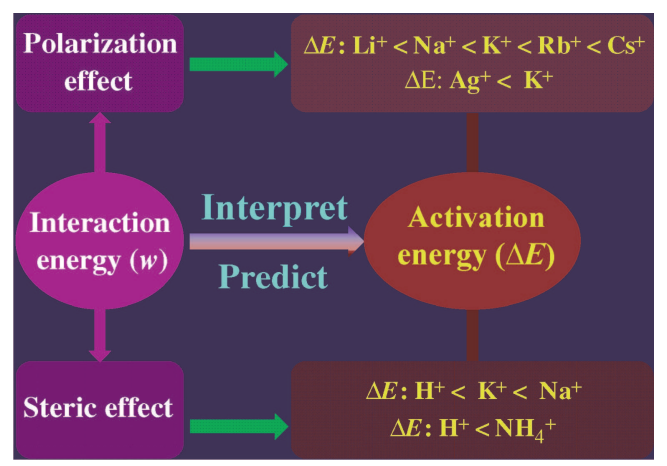

Scheme 1. Correlation between the interaction energies $(w)$ resulted from polarization or steric effect and the activation energies $(\Delta E)$ for the aggregation of colloidal particles in ionic solutions. 
facilitates the aggregation of colloidal particles corresponding to smaller activation energy $(\Delta E)$ (scheme 1). Owing to the apparently softer electronic configuration, $\mathrm{Ag}^{+}$rather than $\mathrm{K}^{+}$will be much more polarized by the external electric fields. The trend of activation energies for these two cations $\left(\mathrm{Ag}^{+}<\mathrm{K}^{+}\right)$can be interpreted by interaction energies $(w)$, in a similar way as that for the various alkali cations (scheme 1). It is thus assumed that larger interaction energy $(w)$ corresponds to smaller activation energy $(\Delta E)$. The definite role of interaction energies has been discussed by before that the adsorption and enrichment of counterions at montmorillonite surfaces facilitate the coagulation processes. ${ }^{45}$

The relationship between interaction energy $(w)$ and activation energy $(\Delta E)$ is further reinforced by two cation Hofmeister series: (1) $\mathrm{H}^{+}$vs. $\mathrm{K}^{+}$, (2) $\mathrm{H}^{+}$vs. $\mathrm{NH}_{4}^{+}$, see scheme 1 . The steric effect indicates that the interaction energy $(w)$ of $\mathrm{H}^{+}$with montmorillonite particles is by far larger than those of the other cations, and this can finely interpret the three cation Hofmeister series characterized by activation energies $(\Delta E)$ and the unusual ion specificity for $\mathrm{H}^{+}$. Meanwhile, it is substantiated that larger interaction energy $(w)$ will result in smaller activation energy $(\Delta E)$, and the experimentally observed specific ion effects can thus be interpreted by interaction energies $(w)$.

As compared to other cations, the ionic radius of $\mathrm{H}^{+}$ can be almost neglected ( 0.98 vs. $0.00008 \AA$ for $\mathrm{Na}^{+}$ and $\mathrm{H}^{+}$, respectively). On basis of the ion exchange experimental data available to us, the interaction energy expressions for $\mathrm{H}^{+}$and $\mathrm{Na}^{+}$adsorption on the montmorillite surfaces can be written as, ${ }^{43}$

$$
\begin{gathered}
w_{H}=-F \varphi(x) \\
w_{N a}=-0.19 F \varphi(x)
\end{gathered}
$$

According to Eqs. (10) and (11), the interaction energy ratio of $\mathrm{H}^{+}$vs. $\mathrm{Na}^{+}\left(w_{H} / w_{\mathrm{Na}}\right)$ is calculated to be 5.26. Note that different from the exact interaction energies, the ratios are not so dependent on montmorillite properties. As aforementioned, the activation energies $(\Delta E)$ represent functions of ionic concentrations, and the ratios of $\Delta E_{\mathrm{K}}$ vs. $\Delta E_{\mathrm{H}}$ change within $3.46 \sim 4.14$ for $9.0 \sim 15.0 \mathrm{mmol} / \mathrm{L}$, with the average value of 3.80 . $\mathrm{K}^{+}$should have a larger interaction energy than $\mathrm{Na}^{+}$ $\left(w_{\mathrm{K}}<w_{\mathrm{Na}}\right)$ and this resembles to the scenario of $\mathrm{Ca}^{2+}$ vs. $\mathrm{Mg}^{2+}{ }^{43}$ Thus, the theoretical interaction energy and experimental activation energy ratios can be correlated with each other in a nearly quantitatively manner. This corroborates that the unusual aggregation kinetics, particularly strong ion specificity in $\mathrm{H}^{+}$solutions, should be caused by steric effect (scheme 1). Meanwhile, further improvement to the EDL theory (Eq. 9) is required in order to respond properly to the change of ionic concentrations.

\section{Conclusions}

The aggregation kinetics of colloids represents one of the cornerstone issues in current studies, where specific ion effects can play a decisive role. In this work, the dynamic light scattering technique has been used to in situ monitor the aggregation processes of montmorillonite particles in different ionic solutions $\left(\mathrm{HNO}_{3}\right.$, $\mathrm{NaNO}_{3}, \mathrm{KNO}_{3}, \mathrm{AgNO}_{3}$ and $\mathrm{NH}_{4} \mathrm{NO}_{3}$ ), and the main conclusions are summarized below.

The hydrodynamic diameters, TAA rates and activation energies clearly show that the aggregation kinetics of montmorillonite particles in ionic solutions are dependent on particle density, and lower particle density results in higher activation energy; nonetheless, Hofmeister series will not be affected. The critical coagulation concentrations $(C C C)$ are equal to 25.6, 78.9, 139.7, 41.9 and $35.6 \mathrm{mmol} / \mathrm{L}$ in $\mathrm{H}^{+}, \mathrm{K}^{+}, \mathrm{Na}^{+}, \mathrm{Ag}^{+}$and $\mathrm{NH}_{4}^{+}$solutions, and the value of $\mathrm{H}^{+}$is definitely smaller than those of the other cations. The activation energies for the aggregation of montmorillonite particles in $\mathrm{H}^{+}$, $\mathrm{K}^{+}, \mathrm{Na}^{+}, \mathrm{Ag}^{+}$and $\mathrm{NH}_{4}^{+}$solutions are derived as functions of ionic concentrations, and below $C C C$ increase as $\mathrm{Na}^{+}<\mathrm{K}^{+}<\mathrm{NH}_{4}^{+}<\mathrm{Ag}^{+}<\mathrm{H}^{+}$. All these indicate that the aggregation occurs apparently faster in $\mathrm{H}^{+}$rather than in other ionic solutions and $\mathrm{H}^{+}$should correspond to the unusual ion specificity.

It has been sufficiently testified that the interaction energies between colloidal particles and adsorbed ions are finely correlated with the activation energies for colloidal aggregation. For the various alkali cations $\left(\mathrm{Li}^{+} \sim\right.$ $\mathrm{Cs}^{+}$) and $\mathrm{K}^{+}$vs. $\mathrm{Ag}^{+}$, the interaction energies differ mainly in polarization effect, while for $\mathrm{H}^{+}$vs. $\mathrm{K}^{+}$and $\mathrm{H}^{+}$vs. $\mathrm{NH}_{4}^{+}$, the interaction energies differ mainly in steric effect. All these cation Hofmeister series indicate that larger interaction energies will result in smaller activation energies, and the experimentally observed specific ion effects can be interpreted by interaction energies. An attempt has been made to quantitatively estimate the ion specificity for $\mathrm{H}^{+}$by correlating the interaction energy and activation energy ratios; in addition, it has been substantialized that the unusual ion specificity of $\mathrm{H}^{+}$is caused by steric effect.

\section{Acknowledgements}

This work was financially supported by the National Natural Science Foundation of China (41201223, 41371249 and 21473137), Fundamental Research Funds for the Central Colleges (SWU113049 and 
2362014xk01) and Specialized Research Fund for the Doctoral Program of Higher Education (20110182120 002).

\section{References}

1. Aurell C and Wistrom A 2000 Colloids Surf., A 168 277

2. Ferrone F 1999 Method Enzymol. 309256

3. Molina-Bolívar J, Galisteo-González F and HidalgoÁlvarez R 1997 Phys. Rev. E 554522

4. Wang H, Burgess R, Cantwell M, Portis L, Perron M, Wu F and Ho K 2014 Environ. Toxicol. Chem. 33 1023

5. Haynes D, Lansman J, Cahill A and Morris S 1979 BBABiomembranes 557340

6. Morris S, Chiu V and Haynes D 1979 Mol. Membr. Biol. 2163

7. Bezot P, Hesse-Bezot C, Rousset B and Diraison C 1995 Colloids Surf., A 9753

8. Verwey E and Overbeek J 1948 In Theory of the stability of lyophobic colloids (Elsevier: New York) p. 631

9. Missana T and Adell A 2000 J. Colloid Interf. Sci. 230 150

10. Boström M, Deniz V, Franks G and Ninham B 2006 Adv. Colloid Interf. Sci. 123-126 5

11. Ninham B and Yaminsky V 1997 Langmuir 132097

12. Ninham B, Duignan T and Parsons D 2011 Curr. Opin. Colloid Interf. Sci. 16612

13. Para G, Jarek E and Warszynski P 2006 Adv. Colloid Interf. Sci. $\mathbf{1 2 2} 39$

14. Kershner R, Bullard J and Cima M 2004 Langmuir 20 4101

15. Kim H, Lee H, Lee G, Kim H and Cho M 2012 J. Chem. Phys. 136124501

16. Date M and Dominy B 2013 Commun. Comput. Phys. 1390

17. Salis A, Bilanicova D, Ninham B and Monduzzi M 2007 J. Phys. Chem. B 1111149

18. Bauduin P, Nohmie F, Touraud D, Neueder R, Kunz W and Ninham B 2006 J. Mol. Liq. 12314

19. Pakulova O, Gorobchenko O, Nikolov O, Adelyanov A, Pastukhova S and Bondarenko V 2013 Mater. Wiss. Werkst. Tech. 44167
20. Zhang Y, Furyk S, Bergbreiter D and Cremer P 2005 J. Am. Chem. Soc. 12714505

21. Wang M, Wang Y, Yu D, Han Y and Wang Y 2013 Colloid Polym. Sci. 2911613

22. Thormann E 2012 RSC Adv. 28297

23. Grover P and Ryall R 2005 Chem. Rev. 1051

24. Broering J and Bommarius A 2005 J. Phys. Chem. B 109 20612

25. López-León T, Ortega-Vinuesa J and Bastos-González D 2012 Chem. Phys. Chem. 132382

26. Holthoff H, Egelhaaf S, Borkovec M, Schurtenberger P and Sticher H 1996 Langmuir 125541

27. Jia M, Li H, Zhu H, Tian R and Gao X 2013 J. Soil Sediment $\mathbf{1 3} 325$

28. Tian R, Yang G, Li H, Gao X, Liu X, Zhu H and Tang Y 2014 Phys. Chem. Chem. Phys. 168828

29. Gouy G 1910 J. Phys. Radium 9457

30. Chapman D 1913 Philo. Mag. 25475

31. Debye P and Hückel E 1923 Phys. Z. 24185

32. Stern O 1924 Zeit. Elektrochem. 30508

33. Grahame D 1953 J. Chem. Phys. 211054

34. Bokade V and Yadav G 2007 J. Nat. Gas Chem. 16186

35. Karaborni S, Smit B, Heidug W, Urai J and Oort E 1996 Science 2711102

36. Pedarla A, Chittoori S and Puppala A 2011 Transp. Res. Rec. 91

37. Chittoori B and Puppala A 2011 J. Geotech. Geoenviron. Eng. 137997

38. Bandgar B, Pandit S and Sadavarte V 2001 Green Chem. 3247

39. Yadav G and Doshi N 2002 Appl. Catal. A-Gen. 236129

40. Edelman C and Favejee J 1940 Z. Krist.-Cryst. Mater. 102417

41. Xiong Y, Chen J and Zhang J 1985 In Soil Colloid (2): Methods for soil colloid research (In Chinese) (Beijing: Science Press) p.10

42. Tian R, Li H, Zhu H, Liu X and Gao X 2013 Soil Sci. Soc. Am. J. 77774

43. Liu X, Yang G, Li H, Tian R, Li R, Jiang X, Ni J and Xie D 2014 RSC Adv 41189

44. Marcus Y 1997 In Ion properties (New York: Marcel Dekker)

45. Lagaly G and Ziesmer S 2003 Adv. Colloid Interface Sci. 100-102 105 